\title{
Ghrelin receptor ligands: From the bench to the drug on the market
}

\author{
Jean-Alain Fehrentz ${ }^{1}$, Vincent Guerlavais ${ }^{2}$, Cine M'Kadmi $^{1}$, Marjorie Damian ${ }^{1}$, Sophie Mary ${ }^{1}$, Didier Gagne ${ }^{1}$, Mathieu \\ Maingot $^{1}$, Khoubaib Ben Haj Salah ${ }^{1}$, Severine Denoyelle ${ }^{1}$, Jean-Louis Banres ${ }^{1}$, Jacky Marie ${ }^{1}$, Jean Martinez ${ }^{1}$ \\ ${ }^{1}$ IBMM, UMR 5247, Facult de Pharmacie, Montpellier, France \\ ${ }^{2}$ Aileron Therapeutics, Cambridge, MA, United States
}

https://doi.org/10.17952/35EPS.2018.033

Growth hormone is essential for the development of the child, but also for the hormonal balance of the adult. To play its role, it must be produced and released into the body. This secretion is controlled by another hormone, ghrelin, which is partly produced in the brain (pituitary gland) and which, by binding to its receptor named growth hormone secretagogue receptor or GHSR, releases growth hormone.

Ghrelin receptor or GHSR is a G protein-coupled receptor (GPCR) that mediates, among others, ghrelininduced growth hormone $(\mathrm{GH})$ secretion, food intake, and reward-seeking behaviors. Because of its possible implication in several physiological disorders such as obesity and drugs/alcohol addictions, GHS-R1a represents a major target for the development of therapeutic small molecules.

As part of a European research program to identify molecules that would allow, like ghrelin, to trigger the secretion of growth hormone, we designed and synthesized a new series of compounds including a gemdiamino moiety.[1] After an in vivo structure activity relationship study, a compound - named JMV1843 - able to mimic the action of ghrelin, was chosen for clinical trial. Phase I clinical trial revealed that compound JMV 1843 was well tolerated and no adverse events were reported. Maximal GH release was achieved using a $0.5 \mathrm{mg} / \mathrm{kg}$ dose by oral route. Stimulation of GH appears to be selective as no other hormones measured were affected by administration of JMV 1843 (no effects on ACTH; cortisol; ghrelin; prolactin; insulin and glucose).[2]

After twenty years, from the first in vitro tests to clinical studies on humans, Æterna-Zentaris received at the end of 2017 a marketing authorization by the Food and Drug Administration, the American drug agency, for its application in the diagnosis of growth hormone deficiency, in adults. Its arrival will improve the diagnosis of this pathology that occurs in adults due to a hypothalamic-pituitary disorder (pituitary tumor for example) or brain trauma, which affects about 70,000 people worldwide. While the test used so far (insulin tolerance test) involves restrictive methods including painful injections, the new compound will be ingested orally. By stimulating the release of growth hormone (provided that it is always manufactured by the patient), it will be possible to dose it by blood test. The test will thus make possible to detect a deficiency, but also to dissociate a deficit linked to a non-release of the hormone or to its non-production by the cells, and thus to adapt the therapeutic approaches.

Renamed Macrilen ${ }^{\text {tix }}$, the compound is now marketed in North America by Strongbridge Ireland Ltd. laboratories. It could find other applications, such as the treatment of cachexia (phase 2 clinical study in progress) or stunting in children (application for evaluation filed with the European Medicines Agency). If the IBMMderived molecule JMV1843 is now tracking its course as a pharmaceutical, researchers continue to explore the GHSR receptor. Their goal: to develop compounds that cannot stimulate but block it, and thus propose new approaches to treat obesity, diabetes or addictions. 
<smiles>CC(C)(N)C(=O)N[C@@H](Cc1c[nH]c2ccccc12)C(=O)N[C@@H](Cc1c[nH]c2ccccc12)NC=O</smiles>

Structure of compound JMV 1843

Figure 1: Structure of compound JMV 1843

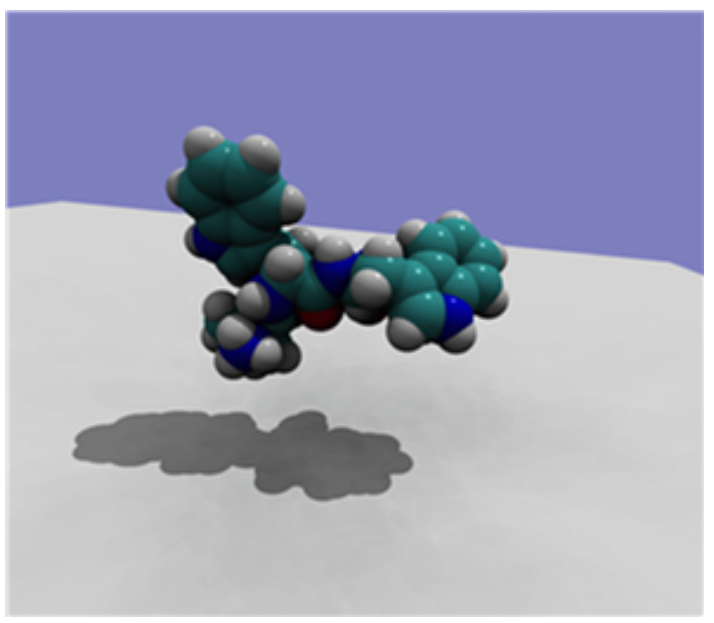

Figure 2: 3D model of compound JMV 1843

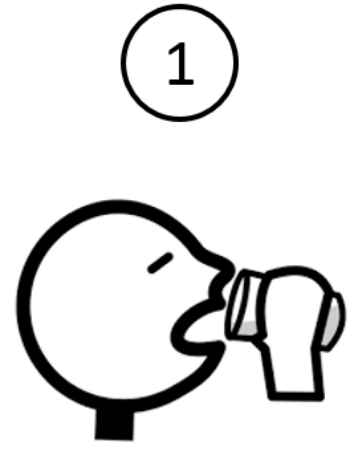

Drink the entire solution $(0,5 \mathrm{mg} / \mathrm{kg})$ within 30 seconds


Your blood will be drawn 4 times at 30, 45, 60 and 90 minutes after you drink the Macrilen solution
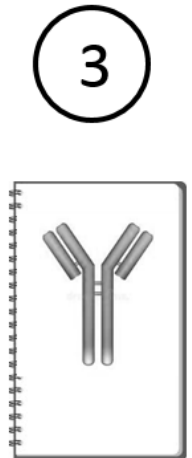

Your blood samples will be analyzed in a specialized lab

to determine the level of stimulated growth hormone

Figure 3: Macrilen test: a real improvement in Growth Hormone dosage!

\section{References}

1. V. Guerlavais et al., A new active series of Growth hormone secretagogues, J. Med. Chem. 2003, 46, 1191-1203.

2. F. Piccoli et al., Pharmacokinetics and Pharmacodynamic Effects of an Oral Ghrelin Agonist in Healthy Subjects, J. Clin. Endocrinol., \& Metabol., 2007, 92, 1814-1820. 